\title{
Accommodation and vergence status among the 3rd and 4th graders in a mainstream school in Gauteng*
}

\author{
IT Metsing $* *$ and JT Ferreira ${ }^{* * *}$ \\ Department of Optometry, University of Johannesburg, PO Box 524, Auckland Park, 2006 South Africa
}

Received July 2011; revised version accepted 5 February 2012

<ingridm@uj.ac.za>

\section{Abstract}

Aim: The data presented in this paper is obtained from the study on the prevalence of visual deficiencies in mainstream and learning disabled schools which revealed no difference in the prevalence of visual deficiencies in both schools. One of the objectives of this study was to determine the visual status of each learner in each of the two groups (mainstream and learning disabled). The findings of the study revealed that both groups presented with different visual deficiencies including accommodation, vergence deficiencies and poor ocular motilities which can contribute towards influencing the children's learning skills negatively. The visual profile on the accommodative and vergence systems of the children from the mainstream school is further analysed in this paper to determine the prevalence of deficiencies in the 8-13 year-olds, and to support inclusion of the evaluation of these visual skills in the school vision screening protocol. Method: One hundred and twelve (112) children had an expanded vision screening, with eighty (80) from the mainstream school in Johannesburg aged 8-13 years. The expanded vision screening included the measurement of visual acuity (Snellen Acuity), refractive error (static retinoscopy), accommodation (accuracy, facility and amplitude), evaluation of the vergence system (accuracy, facility and amplitude) and ocular motilities (direct observation). Of the 80 children from the mainstream school, only 73 children's results were considered and seven subjects were excluded due to their poor responses to the tests.

Kolmogorov-Smirnov test was utilized to assess the normality of distribution of accommodative and vergence status of children from the mainstream school in Gauteng. Depending on the outcome of the normality, the $T$-test was used to analyse the data. The distribution of accommodative and vergence status (amplitudes and facilities) were found to be different from the normal distribution due to $p$-values found to be less than 0.05 . Results: The results indicated that $12.3 \%$ had poor accommodation facility, $10 \%$ had poor accommodation amplitude, $17 \%$ had poor convergence amplitude and $21.9 \%$ had poor vergence facility. The prevalence of poor vergence facility was found to be $21.9 \%$, higher than all the visual efficiency skills evaluated. However, the co-existence of both accommodative and vergence dysfunctions was not found, since subjects presented with either accommodative (isolated) or vergence (isolated) dysfunctions.

Conclusion: The results considered were for tests performed subjectively, and therefore that could have led to the identified statistical outliers (due to inconsistent responses) in the analysis of data for the prevalence of poor accommodative (12.3\%) and vergence $(21.9 \%)$ facility. The prevalence of accommodative and vergence dysfunctions although low in some instances is a concern. There is definitely a need for early identification of visual deficiencies that can impact negatively on the

* This paper includes research from the Masters degree of the first author under the supervision of Professor JT Ferreira 
learning performance of children, especially those of school-going-age. The study therefore supports the expanded vision screening of all school-goingchildren in South Africa to include visual efficiency skills (accommodation and vergence systems) for appropriate and early identification of the barriers to learning. (S Afr Optom 2012 71(1) 22-31)

Key Words: Visual efficiency skills, visual dysfunctions, mainstream school, learning disabled, visual screening, school-going-children.

\section{Introduction}

The human accommodation and vergence systems are amongst the essential visual efficiency skills including visual acuities, refractive errors and motilities required in the process of reading allowing a continuously clear and single image. As children progress from learning to read to reading to learn they encounter common typeface that is smaller, words and letters that are closer together and reading passages are increased in length. Therefore there is an increased demand on their accommodative and vergence systems ${ }^{1}$. Accommodative disorders causing aesthenopic symptoms in younger children (Grade 3 and below) when learning to read are not always apparent, but symptoms such as discomfort and headaches are experienced when the child gets older and becomes more motivated to read ${ }^{1}$. In the presence of accommodative and/or vergence dysfunction, symptoms are commonly reported such as eye strain, blurred vision when changing focus from far to near or vice versa, inability to see small print, the tendency to hold books very close, headaches and diplopia. Accommodative disorders can be identified early when symptoms such as holding the reading material closer are noted by the child's teacher/parent or through an expanded visual screening.

Sometimes patients with accommodative dysfunctions are found to have an associated vergence prob$\mathrm{lem}^{2}$. There is a physiological connection between accommodation and convergence such that when eyes accommodate they converge as well. This process is referred to as accommodative convergence, and is measured by the AC/A ratio. The same is true for when the eyes are converging; they will accommodate and the inter-relationship can be measured using the $\mathrm{CA} / \mathrm{C}$ ratio $^{3,4}$. The relationship between accommodation and convergence is approximately the same throughout life, it does not depend on the amplitude of accommodation decreasing with age but is driven by the stimulus for accommodation ${ }^{4-6}$.

Hoy et al conducted a study on 114 children aged between 9 and 13 years to investigate the relationship between academic achievement and accommodative/ vergence dysfunctions in symptomatic primary school children. Comprehensive eye and vision examinations were conducted on children who met the eligibility criteria, that is, those children who were symptomatic with no amblyopia, strabismus, high refractive errors (contact lens wearers) or ocular and systemic pathology. Accommodative amplitudes (Donder's Push up method) and facility (2 D flippers), near point of convergence and vergence facility ( $8 \mathrm{pd} \mathrm{BO} / \mathrm{BI})$ were evaluated. The results indicated that 82 of the 114 children had non-strabismic accommodative and vergence dysfunctions which had a significant relationship to their academic performance scores (reading, mathematics, social science and science). Hoy et al concluded that it is essential for accommodative and vergence functions to be tested in all children with academic difficulties and visual symptoms.

In further investigating the relationship between accommodation and vergence dysfunctions a study was conducted on 299 elementary school children average age of $11.5 \pm 0.63$ years to determine whether accommodation insufficiency is the primary source of symptoms in children with convergence insufficiency $^{5}$. Accommodation amplitude and facility were evaluated using the Donders Pushup method and 2 D flippers respectively. The vergence system was evaluated using Von Graeffe and nearpoint of convergence tests. The test results were used to categorize subjects into four groups that is, those with normal binocular vision, convergence insufficiency (isolated), accommodation insufficiency (isolated), or accommodation and convergence insufficiency (associated). The results of the study revealed that convergence insufficiency can occur in isolation without compromised 
accommodation. The co-existence of both convergence and accommodation insufficiency was found to increase with the severity of the symptoms ${ }^{4,8}$.

In terms of the National Health Policy for South Africa ${ }^{9}$ vision impairment was identified as potentially one of the hindrances to a child's learning performance and development. One of the objectives of the policy was to address barriers to learning which included vision impairment, in order to facilitate maximum benefit from education. Health workers lead by a professional nurse in terms of the school health policy perform the vision screenings in most schools in Gauteng. Moodley ${ }^{10}$ indicates that the screenings done by the health workers are based mainly on the measurement of visual acuities. In taking visual acuities only to screen for visual deficiencies, one is most likely to fail to identify accommodation and vergence dysfunctions impacting negatively on academic performance of the child.

\section{Accommodation dysfunction}

Accommodation is defined as the ability of the intraocular lens to increase its convexity, altering the eye's dioptric power and thus enabling light diverging from a near source to be focused upon the retina in order to obtain a clear image ${ }^{11-13}$. Disorders of accommodation are divided into four categories namely insufficiency, excess, infacility and ill-sustained ${ }^{11}$. A complete evaluation of the accommodative system including the amplitude, accuracy and facility is therefore essential for appropriate diagnosis and management of patients presenting with symptoms related to accommodation dysfunction ${ }^{14}$. Several studies ${ }^{15-21}$ investigated the prevalence of accommodation dysfunctions in school-going-children. However, different aspects of accommodative dysfunctions, for example, amplitude, facility, and accuracy were researched and evaluated separately.

Moodley ${ }^{10}$ conducted a study to investigate the dysfunctions of accommodation including the amplitude, facility and accuracy in the primary school children. Two hundred and sixty four (264) primary school children with their ages ranging from 6 to 13 years had their vision evaluated. The amplitude, facility and accuracy of accommodation were evaluated monocularly and binocularly using Donder's Push up Method, 2 D flippers and MEM retinoscopy respec- tively. The study revealed that more than a quarter of the children tested had some form of accommodation anomalies, for example accommodation insufficiency, infacility, or high lag/lead. In conclusion it was therefore reccomended that regular and comprehensive vision screenings for primary school children were essential.

\section{Vergence deficiencies}

Vergence eye movements are defined as disjunctive movements occurring when fixation is changed from a distant to a closer object or vice vers $a^{11-13}$. The vergence system depends on tonic innervation to the extra-ocular muscles, accommodation and perceived distance of the object of interest (proximal), enabling the visual axes to converge, for the image of the object of interest to be maintained on the fovea of each eye for the provision of high resolution. Near and far horizontal and vertical phorias, near and far positive and negative fusional vergences, vergence facility and nearpoint of convergence are the visual parameters that are used to evaluate the vergence system ${ }^{6,7}$.

In fully evaluating the vergence system it is important that absolute and relative convergences are evaluated. The three important components of absolute convergence assessed should include the amplitude, facility, and stamina, which can be assessed using the near point of convergence test. The presence of normal fusion amplitude does not rule out the dysfunction of the fusional vergence system ${ }^{6}$. The other characteristics of the vergence system including poor vergence facility, and reduced near point of convergence could also contribute to vergence dysfunction. Therefore in fully evaluating the vergence system in the presence of the normal fusion amplitudes it is important to conduct the additional tests of the vergence facility and near point of convergence ${ }^{14,22,23}$.

Heterophoria is referred to as the latent deviation requiring fusional vergence to maintain single binocular vision ${ }^{14}$. The smooth functioning of the heterophorias especially at near is important for the near task of reading. Several other studies ${ }^{24-29}$ found a higher prevalence of lower fusional reserves in children with reading disabilities compared to children without reading disability. It was therefore concluded that vergence dysfunctions adversely affected children's educational performance. 
The nearpoint of convergence test is frequently used to evaluate convergence insufficiency but normative data for children was not available until about $1998^{30}$. The variance in the normal data for children when evaluating the NPC is caused by different targets recommended by various researchers, and the different targets recommended varied from using the accommodative target, penlight torch with red lens or red-green anaglyphs ${ }^{31}$.

The prisms of choice for evaluating vergence facility were found to vary from one researcher to another. The discrepancies in the prism powers to be utilized in evaluating the vergence facility varied from $3 \mathrm{pd}$ base-in/12pd BO, 4pd BI/ 8pd BO and 8pd BI/ 8pd $\mathrm{BO}^{32-34}$.

\section{Method}

A cross-sectional survey was conducted with the visual efficiency skills of the 3rd and 4th graders aged between 8 and 13 years old evaluated. Purposive sampling was used to select the subjects in grades 3 to 4 . The research record card was designed by the principal investigator for the recording of visual variables evaluated to collect data. The visual evaluations were done by the principal investigator as well as by 18 fourth year optometry students from the University of Johannesburg under her supervision. The fourth year students involved in the study had a workshop conducted by the principal investigator prior to the data collection, in order to orientate them on how to do the visual evaluations (emphasis was on the targets used, methods, time factor, postures and illumination) for the standardization of the tests.

The visual evaluations were done in the morning from $09 \mathrm{~h} 00$ until 11h30, with each child evaluated for approximately 25 minutes. The students under the supervision of the principal investigator evaluated the respondents in pairs. Every 25 minutes approximately five children were visually screened. The evaluations were divided into different stations for measuring visual acuities, retinoscopy (static and dynamic), ocular motilities, accommodation (facility and amplitude), cover test with near point of convergence, smooth vergences and vergence facility. The children evaluated were kept in a separate room, made available by the participating school. The visual skills evaluated included visual acuities, refractive errors, accommo- dation, vergence and ocular motilities. The methods for the evaluation of accommodation and vergence system will be discussed below for the purpose of this study.

The ability of the accommodative system to change focus from stimulation to relaxation was assessed binocularly using $2 \mathrm{D}$ flipper lenses. The children were given targets that required good focus (6/9 letters) at $40 \mathrm{~cm}$ while the lens power was changed from plus to minus and each eye was evaluated for one minute. The target used was the Bernell Vectogram Acuity/ Suppression slide (SO/V9) with the subjects wearing the Polaroid lenses to monitor for suppression. The Polaroid lenses enabled the right eye to see the letters in row number four (\#4) and the left eye to see the letters in row number six (\#6). The letters in row number five (5) were seen by both eyes. The facility of accommodation was regarded as normal for the age group (8-13 years), monocularly should they achieve $7(+/-2)$ cycles per minute $(\mathrm{cpm})$ and binocularly if they achieved $5(+/-2 \mathrm{cpm})$. Children without accommodation infacility were regarded as having failed the test $^{35}$.

The maximum amount of accommodation the eye is capable of, referred to as the amplitude of accommodation was determined monocularly using the push-up method. The accommodative amplitude was measured in centimeters $(\mathrm{cm})$ and then converted to diopters (D). The expected maximum and minimum amplitudes of accommodation for a child of a given age were determined using Hofstetter's (1950)6 formulas. If the amplitude was 1D or more above age average it was regarded as strong and ranked number 5, an amplitude of 4D or more below age average was regarded as very weak and ranked number one ${ }^{6}$. A decrease of the amplitude of accommodation with repeated measurements (approximately five times) indicated ill-sustained accommodation ${ }^{14}$. A difference of amplitude of accommodation more than 2D between the two eyes was regarded as ill-sustained.

The amplitude and efficiency of the vergence system were measured using the nearpoint of convergence (NPC) test. A break point greater than $8 \mathrm{~cm}$, with the recovery more than $10 \mathrm{~cm}$ were considered abnormal, with the red lens a greater recession more than $7 \mathrm{~cm}$ for break and more than $10 \mathrm{~cm}$ for recovery suggested a significant convergence problem ${ }^{14}$. The flipper prisms $8 \mathrm{pd} \mathrm{BI/BO}$ mounted in a flipper device 
were put in front of the eyes and respondents were informed that initially the letters will be double. Respondents were further instructed to attempt to make the fixated letters clear and single, and to report that to the examiner as soon as that takes place. For the purpose of this study, the expected norms considered were those according to Atkinson et al. (1980) (as discussed in Jimenez et al. 2004) ${ }^{36}$ indicated in Table 1 below, since suppression in this study was not monitored. Vergence facility was subjectively evaluated at near $(40 \mathrm{~cm})$ with the $8 \mathrm{pd} \mathrm{BI} / \mathrm{BO}$ mounted in a flipper device.

\section{Results}

The number of subjects examined in this study was initially 80 but seven subjects were excluded from the study due to their poor responses to all the tests performed on them. The seventy three (73) subjects with valid responses included $34(46.6 \%)$ males and 39 $(53.4 \%)$ females. The subject's ages ranged from 8 to 13 years with the mean of $9.70(+/-0.811)$ years and a median age of 10 years. The visual skills evaluated included the visual acuities, refractive errors, accommodation, vergence and ocular motilities

Table 1 Clinical Criteria

\begin{tabular}{|l|l|l|l|}
\hline Visual skill evaluated & Method used & Normal & Below Normal \\
\hline faccommodation & $+/-2 \mathrm{D}$ flippers & OU: $5(+/-2) \mathrm{cpm}$ & OU: $\geq 3 \mathrm{cpm}$ \\
\hline Accommodation & Donder's Push-up Method & 1 D or more above & -4 D or more below \\
& & average & age average \\
& & & Difference of more \\
& & than 2 D between the & two eyes \\
\hline Convergence & NPC & Break: $5(+/-2.50) \mathrm{cm}$ & Break: $>8 \mathrm{~cm}$ \\
\hline Vergence facility & Vergence facility & $6.5( \pm 4.0) \mathrm{cpm}$ & $<2.5 \mathrm{cpm}$ \\
\hline
\end{tabular}

Table 2 The sample size in terms of gender

\begin{tabular}{|l|l|l|l|l|l|}
\hline Gender & Frequency & Percent & Valid & \multicolumn{2}{l|}{ Cumulative } \\
\hline & & & & Percent & Percent \\
\hline \multirow{3}{*}{ Valid } & Male & 34 & 46.6 & 46.6 & 46.6 \\
\cline { 2 - 7 } & Female & 39 & 53.4 & 53.4 & 100.0 \\
\cline { 2 - 7 } & Total & 73 & 100.0 & 100.0 & \\
\hline
\end{tabular}




\section{Accommodation Facility}

Accommodation facility ranged from 0 to $14 \mathrm{cpm}$, with a mean of $5.84( \pm 2.635) \mathrm{cpm}$. The median was $6 \mathrm{cpm}$ as indicated in Figure 1 below. The subjects with the zero facility could not clear either $+2 \mathrm{D}$ or $-2 \mathrm{D}$ lenses and thus were regarded as having failed the test. They were included in the analysis of data because failing the test meant that they could not stimulate or relax their accommodation system. Six $(8.2 \%)$ subjects could not stimulate nor relax their accommodation and they were classified as having poor accommodation facility. However, only three (4.1\%) subjects had below normal accommodation facility and therefore the total prevalence of poor accommodation facility was found to be $12.3 \%$.

Figure 1 below shows a spread of the distribution of accommodation facility from 4 to $6 \mathrm{cpm}$ in the first $(26 \%)$ and second (31.5\%) quartile below the median. In the third quartile, Figure 1 below indicates a high concentration $(34.3 \%)$ of accommodation facility from 6 to $7 \mathrm{cpm}$ thus resulting in the distribution of our findings skewed to the left.

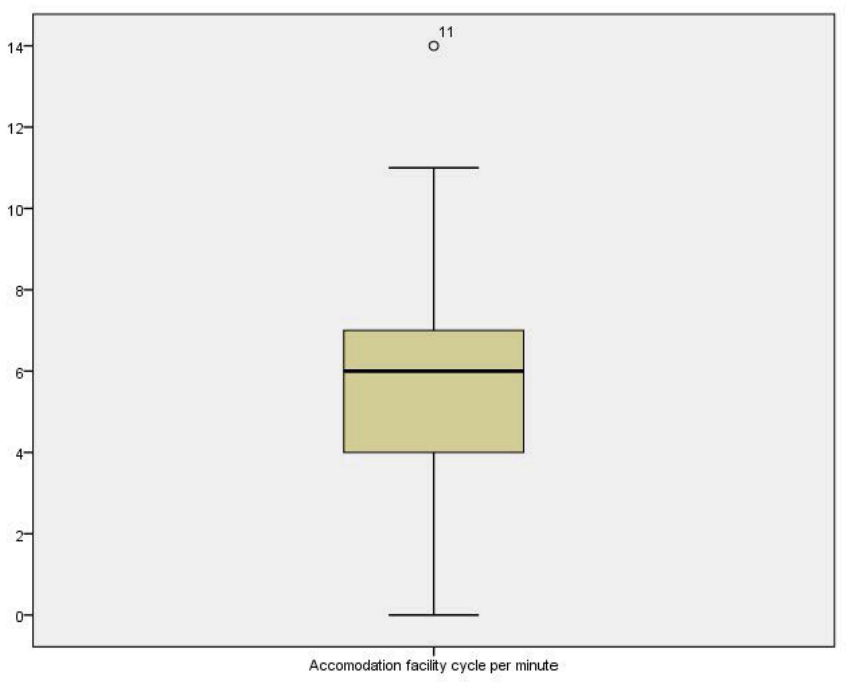

Figure 1 Distribution of accommodation facility
According to the Kolmogorov-Smirnov test, $T=$ 0.120 and $p$-value $=0.011$ (refer to Table 3 below). The $p$-value was therefore found to be less than 0.05 , leading to the rejection of the null hypothesis and the conclusion that the distribution of accommodation facility measured on the subjects was different from that of the normal distribution.

\section{Amplitude of accommodation}

The amplitude of accommodation was evaluated monocularly and ranged from 8 to $25 \mathrm{D}$ for both the left and right eyes with means of $13.7( \pm 4.1) \mathrm{D}$ and $13.9( \pm 4.29) \mathrm{D}$ respectively. The medians for the amplitude of accommodation of the right and left eyes were both found to be equal, that is, $13 \mathrm{D}$. The total prevalence of subjects with amplitudes of accommodation below normal for the left and right eyes was found to be $8.2 \%$ and $9.6 \%$ respectively.

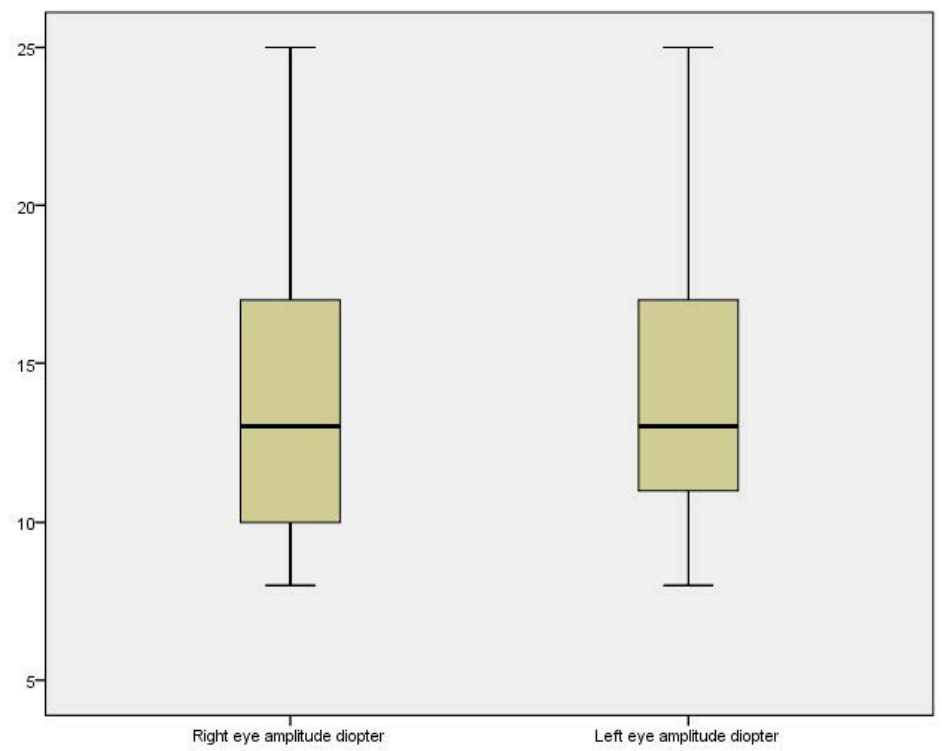

Figure 2 Distribution of amplitudes of accommodation for the right and left eyes

Table 3 Tests of normality for accommodative and vergence facility and nearpoint of convergence

\begin{tabular}{|c|c|c|c|c|c|c|}
\hline \multicolumn{7}{|l|}{ Tests of Normality } \\
\hline & \multicolumn{3}{|c|}{ Kolmogorov-Smirnov } & \multicolumn{3}{|c|}{ Shapiro-Wilks } \\
\hline & Statistic & df & Sig. & Statistic & df & Sig. \\
\hline Age & 0.259 & 73 & 0.000 & 0.805 & 73 & 0.000 \\
\hline Accommodation Facility & 0.120 & 73 & 0.011 & 0.945 & 73 & 0.003 \\
\hline NPC Break & 0.130 & 73 & 0.004 & 0.961 & 73 & 0.023 \\
\hline NPC Recovery & 0.160 & 73 & 0.000 & 0.955 & 73 & 0.011 \\
\hline Vergence Facility & 0.178 & 73 & 0.000 & 0.915 & 73 & 0.000 \\
\hline
\end{tabular}


Possible outliers were found to be amplitudes of accommodation above $20 \mathrm{D}$ due to the subjects perhaps not understanding the test and therefore responding poorly. The outliers have therefore influenced our data distribution, with normal and above normal amplitudes of accommodation prevalent in $71.2 \%$ and $86.4 \%$ for the right and left eye respectively as seen in Figure 2 above. According to Figure 2 above, there appears to be the wider distribution of the range of values between 13 and $17 \mathrm{D}$ for the left and right eye in the third quartile. The first quartile for the right eye is smaller $(8-19 \mathrm{D})$ than that of the left eye $(8-11 \mathrm{D})$ with the second quartile showing a wider spread (10$13 \mathrm{D})$ and for the left eye (11-13 D). The prevalence of amplitudes of accommodation below normal ranging from 8 to $9 \mathrm{D}$, were found to be more $(9.6 \%)$ in the left eye compared to the right eye $(8.2 \%)$.

Table 4 Tests of normality for accommodative amplitudes of the right (RE) and left (LE) eyes

\begin{tabular}{|c|c|c|c|c|c|c|}
\hline \multicolumn{7}{|c|}{ Tests of Normality } \\
\hline & \multicolumn{3}{|c|}{ Kolmogorov-Smirnov } & \multicolumn{3}{|c|}{ Shapiro-Wilks } \\
\hline & Statistic & df & Sig. & Statistic & df & Sig. \\
\hline Amplitude RE & 0.184 & 73 & 0.000 & 0.901 & 73 & 0.000 \\
\hline Amplitude LE & 0.165 & 73 & 0.000 & 0.899 & 73 & 0.000 \\
\hline
\end{tabular}

The statistic values determined using the Kolmogorov-Smirnov test and the corresponding $p$-value are $T=0.184$ and $T=0.165$ for the right and the left eye respectively with the $p$-value $=0.00$ as seen in Table 4 above. Thus the null hypothesis (see Table 4 above) is rejected in both instances, the distributions of amplitudes of accommodation (variable tested) for both the right and left eyes were found to be deviated from the normal distribution.

\section{Convergence amplitude}

The convergence amplitude was evaluated using the nearpoint of convergence test and the breakpoint ranged from 0 to $11 \mathrm{~cm}$ with recovery ranging from 2 to $14 \mathrm{~cm}$. The mean for the break points was determined to be $4.9 \pm 2.387 \mathrm{~cm}$. Eleven $(11 \%)$ percent of the subjects were found to have slightly receded amplitudes of convergence from 9 to $11 \mathrm{~cm}$, and $16.4 \%$ had receded recovery to seeing the target as single and clear as seen in Figure 3 below.

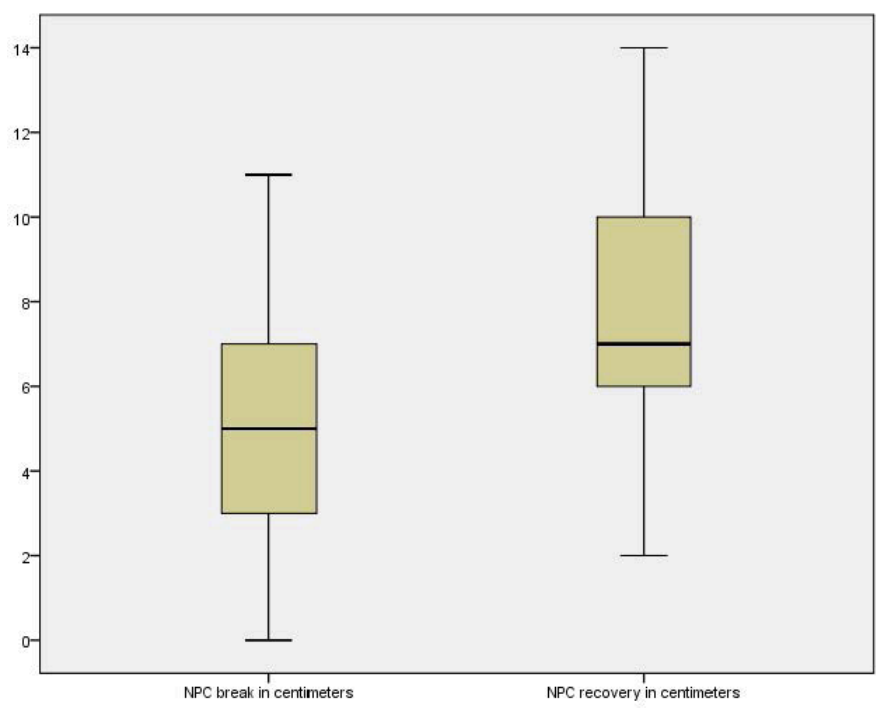

Figure 3 Distribution of convergence amplitudes

According to Figure 3 above, distribution of data below the median (2nd quartile) and above median (3rd quartile) was found to be the same for the break point. However, for recovery our findings were different with a wider spread of distribution (54.8\%) above the median from 7 to $11 \mathrm{~cm}$ in the third quartile, and in the fourth quartile the distribution of below normal 12 to $14 \mathrm{~cm}$ with a prevalence of $10.9 \%$.

The statistic values determined using the Kolmogorov-Smirnov test and the corresponding $p$-value are $T=0.130$ and $T=0.160$ for break and recovery with $p$-values of 0.04 and 0.00 respectively as shown in Table 3 above. The $p$-values for both break and recovery were found to be below 0.05 , the null hypothesis is therefore rejected and a conclusion is reached that there is a difference between the normal distribution and the distribution of nearpoint of convergence evaluated.

\section{Vergence facility}

The vergence facility measured in cycles per minute ranged between zero to $17 \mathrm{cpm}$ with the mean of $5.93 \pm 5.93 \mathrm{cpm}$.

The zero measurement found as indicated in Figure 4 was for those subjects who could not see the test target clearly with either the 8 pd base-out or $8 \mathrm{pd}$ base-in. The total number of subjects with poor vergence facility was $21.9 \%$, with $78.1 \%$ found to have normal to above normal vergence facilities. Statistical outliers were found to be the vergence facility of 17 cpm with a prevalence of $1.4 \%$ and due to inconsist- 
ent responses by the respondent to the test caused by lack of understanding, the distribution of data was therefore influenced. In Figure 4 the distribution of data below the median $(7 \mathrm{cpm})$ ranged from 0 to 8 cpm with a wider spread (41.1\%) of the range of vergence facility between 4-7 cpm and a high concentration $(32.9 \%)$ between $7-8 \mathrm{cpm}$ in the third quartile. The statistic value of Kolmogorov-Smirnov test and the corresponding value were $T=0.178$ with the $p$ value $=0.00$ as shown in Table 3 above. The $p$-value was found to be below 0.05 , leading to the rejection of the null hypothesis and the conclusion that there is a difference between normal distribution and evaluated vergence facility.

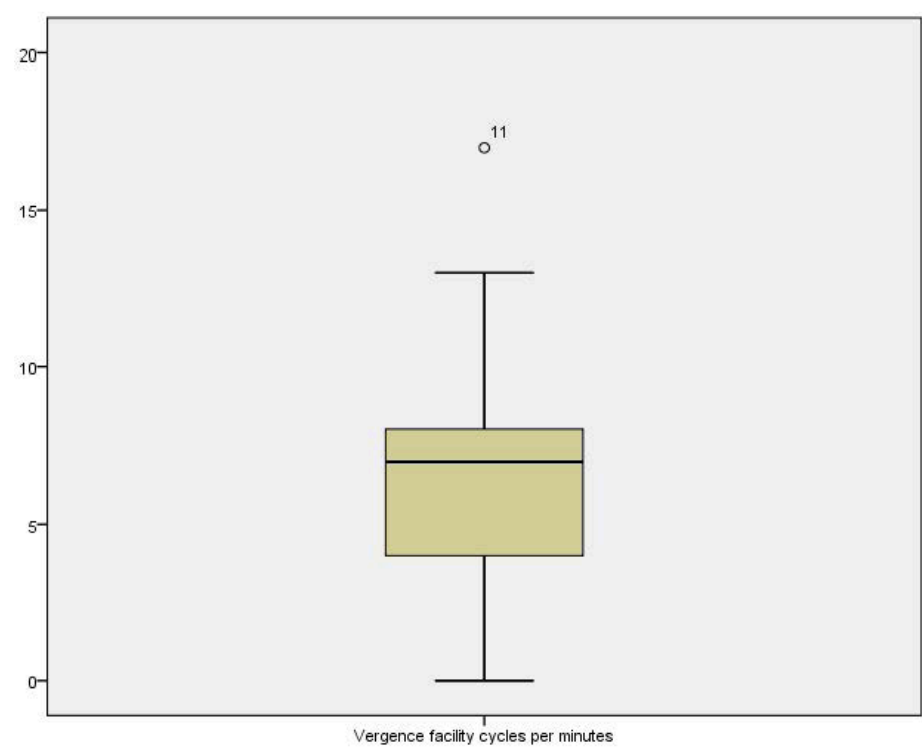

Figure 4 Distribution of vergence facilities

\section{Discussion}

In terms of the National School Health Policy of South Africa (2002) $)^{9}$, vision impairment (including uncorrected refractive errors) was identified as a possible and significant cause of limitations to a child's learning performance and development. One of the objectives of the policy is to identify the limitations to learning, in order to enable children from a younger age (Grade $\mathrm{R}$ and Grade 1 learners) to benefit from education. The vision screenings according to the $\mathrm{Na}-$ tional School Health Policy of South Africa are done by health workers lead by a professional nurse. In a few pre-schools (in South Africa) vision screenings are done by optometrists from private practices as per individual arrangements between the schools and op- tometrists. As indicated by Moodley ${ }^{10}$, vision screenings conducted by school nurses usually only involves the measurement of visual acuities, and therefore other visual efficiency skills including accommodation and vergence dysfunctions may be missed.

Results of this study are derived from the study conducted on the prevalence of visual deficiencies in the learning disabled in Johannesburg. One of the objectives of the study was to determine the visual status of each learner in the two groups of children from the mainstream and learning disabled schools. The study revealed that both groups presented with different visual deficiencies including accommodation, vergence deficiencies and poor ocular motilities which can contribute negatively towards children's learning skills. The visual profile on accommodative and vergence systems of children from mainstream school is further analysed in this paper, to determine the prevalence of deficiencies in the mainstream school children between the ages of 8 to 13 years in order to support inclusion of the evaluation of these visual skills in the school vision screening protocol.

Of the 73 children who responded to the accommodative and vergence tests performed on them, the study indicated that $12.3 \%$ subjects had poor accommodation facility, approximately $10 \%$ had poor amplitudes of accommodation, approximately $17 \%$ had poor convergence amplitudes and $21.9 \%$ had poor vergence facility. Poor vergence facility with the prevalence of $21.9 \%$ was found to be the highest of all visual skills evaluated. These findings agree with several other studies ${ }^{24-28}$ conducted, and supporting that poor visual efficiency skills (including accommodative and/or vergence dysfunction) may contribute to poor academic performance. Inconsistencies in findings of the study were identified whereby subjects did not show the prevalence of the co-existence of both the accommodative and vergence dysfunctions in support of Rouse et al 1999 studies $^{2}$.

The findings of the distribution of accommodative and vergence status were all found to be different from the normal distribution, since $p$-values were found to be less than 0.05 . Various factors could have contributed to the difference in the distribution of visual efficiency skills evaluated that is, accommodative and vergence systems since results considered were on subjective tests. The responses of subjects to tests, 
therefore depended on their maturity and on whether they understood the tests utilised to evaluate their visual efficiency skills.

The high prevalence of subjects who completely failed accommodative (12.3\%) and vergence (21.9\%) facility tests is a clear indication of subjects not responding appropriately to tests performed. Possible outliers were identified when the accommodative and vergence systems were evaluated which lead to the difference between the normal distribution of variables.

In conclusion considering the limitations of this study, it is therefore important for the comprehensive screening to include all the visual efficiency skills, including accommodation and vergence systems for proper and early identification of barriers to learning. The findings of this study are inconclusive due to lack of information on academic performance of subjects involved in the study not provided to the principal researcher by the participating institution. This study did not determine the relationship between the academic performances of subjects and identified visual deficiencies. The important finding from the study was that visual efficiency skills including the accommodative and vergence deficiencies were found in approximately a third of the children in the age group of 8-13 year olds from the mainstream school, and this finding supports the recommendation that the visual screenings should include the evaluation of other visual efficiency skills and not to rely on the measurement of visual acuities only.

\section{References}

1. Rosenbloom AA, Morgan MW. Principles and practice of paediatric optometry. Philadelphia: JB Lippincot Co, 1990 171-479.

2. Rouse WM, Borsting E, Hyman L, Hussein M, Cotter SA, Flynn M, Scheiman M, Gallaway M, Deland, PN. Convergence Insufficiency and Reading Study (CIRS) Group. Frequency of convergence insufficiency among the fifth and sixth graders. Optom Vis Sci (1999) 76 643-649.

3. Scheiman MM, Rouse MW. Optometric management of learning-related vision problems. St Louis: Mosby-Year book, 19949.

4. Lynn FM, Paul ND, Andrew LN. Accommodative Insufficiency is the primary source of symptoms in children diagnosed with convergence insufficiency. Optom Vis Sci 2006 83 E281- E289.

5. Emslie R, Claasens A, Sachs N, Walters I. The near triad and associated visual problems. S Afr Optom 200766 (4) 184-191.

6. Griffin JR. Binocular anomalies. Procedures and vision therapy. 2nd Edition. Chicago, Illinois: Professional. Press 1992 30-52.

7. Hoy SS, Sang CP, Chun MP. Relationship between accommodative and vergence dysfunction and academic achievement for primary school children. Ophthal Physiol Opt 200929 615-624.

8. Jampolsky A. Ocular divergence mechanisms. Edited by Lynn FM, Paul ND, Andrew LN. (2006) Accommodative Insufficiency is the Primary Source of Symptoms in Children Diagnosed with Convergence Insufficiency. Optom Vis Sci 197083 E281- E289.

9. National Department of Health (South Africa). National School Health Policy and Implementation of Guidelines, June 2002.

10. Moodley VR. Amplitude, facility and accuracy of accommodation in a primary school population. $S$ Afr Optom 200867 147-154.

11. Rutstein RP, Daum KM. Anomalies of binocular vision: Diagnosis and management. St. Louis: Mosby, 1998.

12. Rowe F. Clinical orthoptics. 2nd Edition. Oxford: Blackwell Publishing, 1994197.

13. Borish IM. Clinical refraction. USA: Professional Press Books/Fairchild Publication, 1970 91-229.

14. Scheiman MM, Wick B. Diagnostic testing. Clinical management of binocular vision. 2nd Edition. New York: Lippincott Williams \& Wilkins, 2002 4-597.

15. Hoffman LG. The role of the optometrist in the diagnosis and management of learning-related vision problems. In Optometric management of learning related vision problems. Edited by Scheiman, MM \& Rouse, MW St Louis: Mosby, 1994 69-87.

16. Griffin JR, Christenson GN, Wesson MD, Erickson GB. Optometric management of reading disorders. USA: Butterworth-Heinemann, 1997 5-170.

17. Rosner J, Rosner J. Comparison of visual characteristics in children with and without learning difficulties. Am J Optom Physiol Opt 198764 532-3.

18. Burge S. Suppression during binocular accommodative rock. In A review of the literature and a normative study of accommodative facility. Edited by Zellers, J.A., Alpert TL, Rouse MW. J Am Optom Assoc 198455 31-37.

19. Kulp MT, Schmidt PP. Visual predictors of reading performance in kindergarten and first grade children. Optom Vis Sci 199673 255-262.

20. Poytner HL, Schor C, Haynes HM, Hirsch J. Oculomotor functions in reading disability. Am J Optom Physiol Opt 198267 126-140.

21. Leat SJ, Shute RH, Westall CA. Assessing children's vision. A handbook. Oxford: Butterworth-Heinemann, 1999 124-222.

22. Jimenez R, Perez MA, Garcia JA, Gonzalez MD. Statistical normal values of visual parameters that characterize binocular function in children. Ophthal Physiol Opt 2004 
24 528-542.

23. Grisham D. The dynamics of fusional vergence eye movements in binocular dysfunction. Am J Optom Physiol 1980 57 465-655.

24. Grisham D, Simons H. Binocular anomalies and reading problems. J Am Optom Assoc 198758 578-587.

25. Eames TH. Low fusional convergence as a factor in reading disability. Am J Ophthal 193415 709-10.

26. Eames TH. Comparison of eye conditions among 1000 reading failures, 500 ophthalmic patients, and 150 unselected children. Am J Ophthal 194831 713-17.

27. Good GH. A relationship of fusion weaknesses to reading reliability. In Optometric management of learning-related vision problems. Edited by Scheiman, MM \& Rouse, MW. St Louis: Mosby-Year book, 1994169.

28. O'Grady J. The relationship between vision and educational performance: A study of year 2 children in Tasmania. Aust J Optom 198467 126-140.

29. Marcus SE. A syndrome of visual constrictions in the learning disabled child. Am J Optom Assoc 197445 746-749.

30. Hayes GJ, Cohen BE, Rouse WM, and Deland PN. Normative values for the nearpoint of convergence of elementary school children. Optom Vis Sci 199875 506-512.

31. Gall R, Wick B, Bedell H. Vergence facility and target type. Optom Vis Sci 199875 727-730.

32. Buzelli AR. Vergence facility: developmental trends in a school-age population. Am J Optom Physiol Opt 198663 351-355.

33. Scheiman M. Fusional facility. Am J Optom Physiol Opt 198663 76-77.

34. Steuckle LG, Rouse M. Norms for dynamic vergences Southern Carlifonia College of Optometry student research paper. Edited in Gall, R., Wick, B and Bedell, H. Vergence facility and target type. Optom Vis Sci 199875 731-742.

35. Zellers JA, Alpert TL, Rouse MW. A review of the literature and a normative study of accommodative facility. Am J Optom Assoc 198455 31-37.

36. Atkinson F, Moser JE, Rouse M. Vergence facility in a young adult population. In Statistical normal values of visual parameters that characterize binocular function in children. Edited by Jimenez R, Perez MA, Garcia JA, Gonzalez MD. Ophthal Physiol Opt 200424 528-542. 